УДК $57.621 .383 ; 61.621 .383$

\author{
А.А. Антропов ${ }^{1}$, Д.С. Харенко ${ }^{1,3}$, Е.И. Рябчикова ${ }^{2}$, \\ А.В. Бардашева ${ }^{2}$, А.А. Ломзов ${ }^{2}$ \\ ${ }^{1}$ Институт автоматики и электрометрии СО РАН, Новосибирск, Россия \\ ${ }^{2}$ Институт химической биологии и фундаментальной медицины СО РАН, \\ Новосибирск, Россия \\ ${ }^{3}$ Новосибирский государственный университет, Новосибирск, Россия

\section{ВОЗМОЖНОСТЬ ИССЛЕДОВАНИЯ КЛЕТОК ГРИБА CANDIDA ALBICANS \\ С ПОМОЩЬЮ КОМБИНАЦИОННОГО РАССЕЯНИЯ СВЕТА}

В работе показывается возможность исследования клеток гриба Candida albicans методом комбинационного рассеяния света (КРС). Считается, что спектроскопия КРС позволяет изучать химический состав клеток, не разрушая их. Однако при интенсивном освещении живой клетки могут возникать эффекты фотоповреждения, оптического пинцета и спонтанной люминесценции. Установлено, что воздействие лазерного излучения с длиной волны 532,1 нм, средней мощностью в 20 мВт, сфокусированного в пятно порядка 1 мкм, при проведении исследования методом КРС не приводит к разрушению клеточной стенки, но вызывает изменения ультраструктуры клеточных органоидов. Изменения структуры анализировали методом просвечивающей электронной микроскопии ультратонких срезов. Также получены спектры КРС клеток с различной длительностью инкубации.

Ключевые слова: комбинационное рассеяние, спектроскопия, клетки Candida albicans, ультраструктура.

\author{
A.A. Antropov', D.S. Kharenko", ${ }^{1,}$ E.I. Ryabchikova², \\ A.V. Bardasheva ${ }^{2}$, A.A. Lomzov² \\ ${ }^{1}$ Institute of Automation and Electrometry of SB RAS, \\ Novosibirsk, Russian Federation \\ ${ }^{2}$ Institute of Chemical Biology and Fundamental Medicine of the SB RAS, \\ Novosibirsk Russian Federation \\ ${ }^{3}$ Novosibirsk State University, Novosibirsk. Russian Federation
}

\title{
POSSIBILITY OF INVESTIGATION OF CANDIDA ALBICANS FUNGUS CELLS BY RAMAN LIGHT SCATTERING
}

In this paper, we show the possibility of Raman light scattering studies of Candida albicans cells. It is believed that Raman scattering of light allows us to study the spectra of cells without destroying them. However, with intense illumination of a living cell, photo-damage, optical tweezers, and 
spontaneous luminescence can occur. It was found that the laser radiation with a wavelength of $532.1 \mathrm{~nm}$, an average power of $20 \mathrm{~mW}$, focused into a spot of the order of $1 \mu \mathrm{m}$, during the Raman study, do not lead to destruction of the cell wall, but caused changes in the ultrastructure cell organelles. Structural changes were analyzed by transmission electron microscopy of ultra-thin sections. Spectra of cattle cells with different incubation durations were also obtained.

Keywords: Raman scattering, spectroscopy, Candida albicans cells, ultrastructure.

\section{Введение}

Грибки рода Candida присутствуют в составе нормальной микрофлоры у 80 \% людей и нередко вызывают локальные повреждения кожного покрова. При ослаблении иммунитета хозяина они могут приводить к тяжёлым генерализованным кандидозам, которые в отсутствие соответствующего своевременного лечения могут закончиться летальным исходом [1]. Клетки грибка Candida albicans небольшие (5-6 мкм в диаметре) и окружены клеточной стенкой (около 150 нм толщиной), которая служит мощной природной защитой от повреждающих воздействий, в том числе от лекарственных препаратов. Поиск новых противогрибковых соединений является актуальной задачей, для решения которой необходимо всестороннее изучение биологических свойств Candida albicans. Противогрибковый эффект изучают по подавлению роста и размножения клеток, а также по изменению их морфологии [2, 3]. Несомненный интерес представляет использование принципиально иных методов оценки состояния клеток, в частности, анализ спектров и их изменений при воздействии различных препаратов. Целью данной работы была проверка возможности использования метода комбинационного рассеяния света (КРС) для получения информации о химическом составе данных клеток Candida albicans, анализ изменений их ультраструктуры после воздействия лазерного излучения, а также изменений спектров клеток в зависимости от условий инкубации грибка.

Считается, что КРС позволяет изучать спектры клеток, не разрушая их, однако при интенсивном освещении живой клетки могут возникать эффекты фотоповреждения, оптического пинцета, спонтанной люминесценции. Данное явление происходит, когда флуорофор постоянно теряет способность флуоресцировать из-за фотон-индуцированного химического повреждения и ковалентной модификации. При переходе из возбуждённого синглетного состояния в возбуждённое триплетное состояние флуорофоры могут взаимодействовать с другой молекулой с образованием необратимых ковалентных модификаций. 
Триплетное состояние является относительно долгоживущим по отношению к синглетному состоянию, что позволяет возбуждённым молекулам гораздо дольше подвергаться химическим реакциям с компонентами окружающей среды. Среднее число циклов возбуждения и эмиссии, которые происходят для конкретного флуорофора перед фотообесцвечиванием, зависит от молекулярной структуры и местной среды. Некоторые флуорофоры быстро отбеливаются после испускания всего нескольких фотонов, в то время как другие, более прочные, могут проходить тысячи или миллионы циклов до отбеливания. Важным и основным моментом в данной реакции фотообесцвечивания является взаимодействие флуорофора с комбинацией света и кислорода. Реакции между флуорофорами и молекулярным кислородом постоянно разрушают флуоресценцию и дают свободно-радикальные синглетные формы кислорода, которые могут химически модифицировать другие молекулы в живых клетках. Величина фотообесцвечивания вследствие фотодинамических событий является функцией концентрации молекулярного кислорода и проксимального расстояния между флуорофором, молекулами кислорода и другими клеточными компонентами. Фотообесцвечивание можно уменьшить, ограничив время воздействия флуорофоров на освещение или снизив энергию возбуждения. Однако эти методы также уменьшают измеряемый сигнал флуоресценции. При продолжительном повреждении клеток в результате фотопроцессов внутри них могут формироваться люминесцирующие продукты, приводящие к резкому возрастанию спонтанной люминесценции в образцах [4]. Это особенно важно в случае, когда облучаются одиночные клетки, тем более если область облучения соизмерима с размером образца, тогда фотоповреждение может привести к изменению жизнедеятельности клеток или даже к их гибели. Кроме того, наличие спонтанной люминесценции приводит к искажению спектров КРС. В этом случае невозможно определить отдельные спектральные линии, относящиеся к образцу. Эти обстоятельства накладывают дополнительные ограничения на мощность облучения, длину волны и время экспозиции клеток [5] и определяют необходимость изучения возможности использовать клетки C. albicans в качестве объекта исследования методом комбинационного рассеяния. 


\section{Методика эксперимента}

Эксперименты проводились на оригинальной КРС установке [5], схема которой показана на рис. 1.

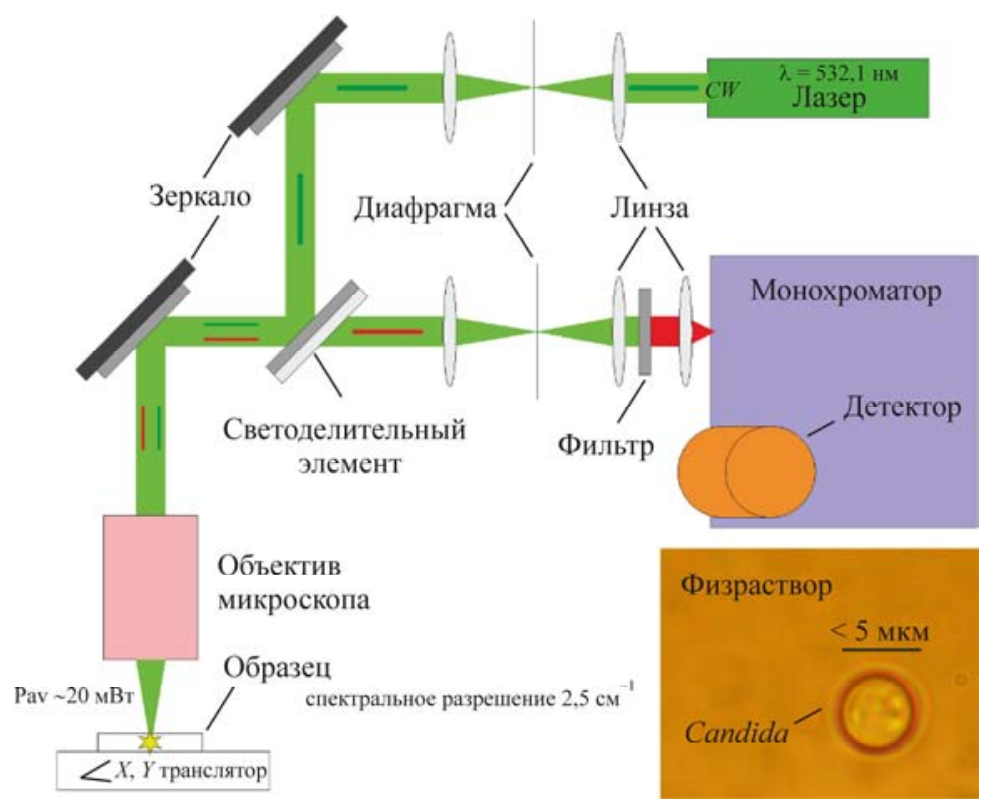

Рис. 1. Схема установки

Для возбуждения комбинационного рассеяния использовалось непрерывное излучение твердотельного лазера лазера (Millennia II; Spectra Physics) с длиной волны 532,1 нм. Данное излучение, проходя через систему линз и диафрагмы, попадает в объектив микроскопа, который фокусирует его на образце. Использовался объектив 100 (PL Fluotar L; Leica), с рабочим расстоянием 4,6 мм и апертурой (NA) = 0,75 . Диаметр сфокусированного пучка измерен экспериментально и составляет 1 мкм. После взаимодействия с образцом рассеянное назад излучение собирается обратно тем же объективом, проходит через фильтр, который поглощает возбуждающее излучение, попадает в монохроматор (SP2500i, Princeton Instruments), где раскладывается в спектр и попадает на многоканальный детектор (Spec-10: 256E/LN, Princeton Instruments). Тем самым мы получаем пространственную зависимость в частотной области. Время экспозиции 60 с, экспозиция 6 Дж. Длины волн для измеренных спектров были откалиброваны 
с помощью неоновой лампы. Погрешность определения абсолютных позиций линий в измеряемых спектрах была не больше $1 \mathrm{~cm}^{-1}$, спектральное разрешение $2,5 \mathrm{~cm}^{-1}$. ПЗС-камера, которая использовалась в качестве детектора, позволяет одновременно снимать весь необходимый нам частотный спектр, покрывающий диапазон от 500 до $3000 \mathrm{~cm}^{-1}$. Такой частотный диапазон обусловлен тем, что в него входит область валентных колебаний простых связей, кратных связей и деформационных колебаний. Диапазон 500-1800 $\mathrm{cm}^{-1}$ также называют «областью отпечатков пальцев», так как положение и интенсивность спектральных пиков сугубо индивидуальны для каждого конкретного органического соединения. Только по полному совпадению частот и интенсивностей линий в этой области спектра можно говорить об идентичности сравниваемых объектов. С помощью микроскопа производилась первичная настройка на изучаемую клетку (см. рис. 1), после чего происходили накопление спектра в течение 60 с и его последующая запись.

Штамм Candida albicans 34 из Коллекции ЭМТК ИХБФМ СО РАН выращивали на агаризованной среде Сабуро, содержащей $1 \%$ пептона, 4 \% глюкозы и $2 \%$ агара при $37^{\circ} \mathrm{C} 24$ ч. Выросшие колонии засевали бактериологической петлей на жидкую питательную среду Сабуро (без агара) и культивировали стационарно при $37^{\circ} \mathrm{C} 24$ ч. Для исследования методом КРС было приготовлено 3 образца: (c1) клетки выдерживали при $4{ }^{\circ} \mathrm{C}$ в течение 5 сут; (с2) клетки инкубировали в течение 2 ч при $37^{\circ} \mathrm{C}$; (exp) клетки в течение 2 ч инкубировали с 20 мкМ/мл синтетического пептида $\mathrm{Arg}_{9} \mathrm{Phe}_{2}$, обладающего выраженной линейной амфифильностью и антибактериальной активностью [6]. Для изучения методом микроскопии комбинационного рассеяния препараты с концентрацией $10^{8}$ клеток грибка/мл C. albicans дважды отмывали от питательной среды физраствором. Для электронно-микроскопического исследования клетки после снятия спектров КРС фиксировали в 4\%-ном растворе параформальдегида, дофиксировали $1 \%$-ным раствором осмиевой кислоты, обезвоживали и заливали в смесь эпон-аралдит по стандартной методике. Изготовленные ультратонкие срезы изучали в просвечивающем электронном микроскопе JEM 1400 (JEOL, Япония). Фотосъемку проводили с помощью цифровой камеры бокового ввода Veleta (EM SIS, Германия). 


\section{Получение и обсуждение результатов}

На первом этапе работы была изучена возможность снятия спектров клеток $C$. albicans, имеющих размеры 5-6 мкм и проверена полнота отмывки препаратов от питательной среды, способной люминесцировать и, соответственно, искажать получаемые спектры. Измерялись спектры отдельных клеток, по очереди. Были проведены измерения от 20 до 30 клеток в каждой суспензии (рис. 2, a). Измерения спектров клеток образцов (c1) и (с2) не выявили значительных различий, однако, отмечалось некоторое изменение высоты пика, соответствующего липидам, вероятно, отражающее их использование в метаболизме клеток. Затем были измерены спектры образцов ехр и с2. Во всех трёх образцах клетки C. albicans были помещены в физиологический раствор.

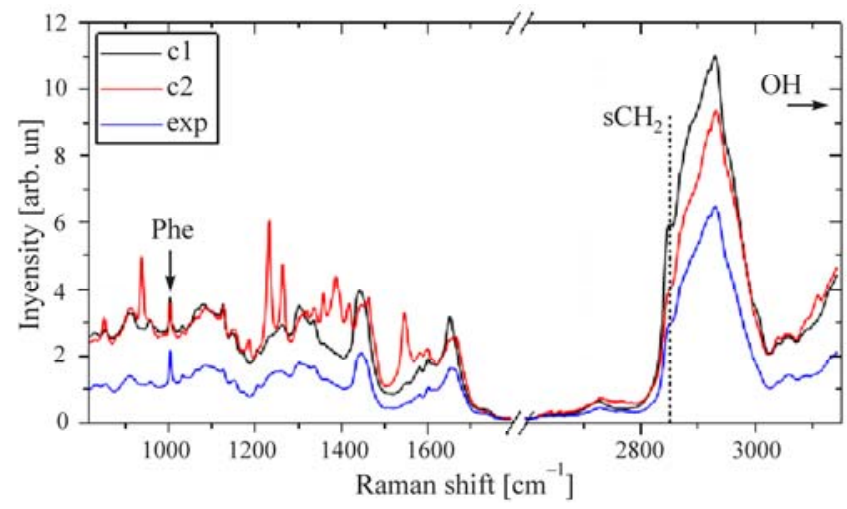

$a$

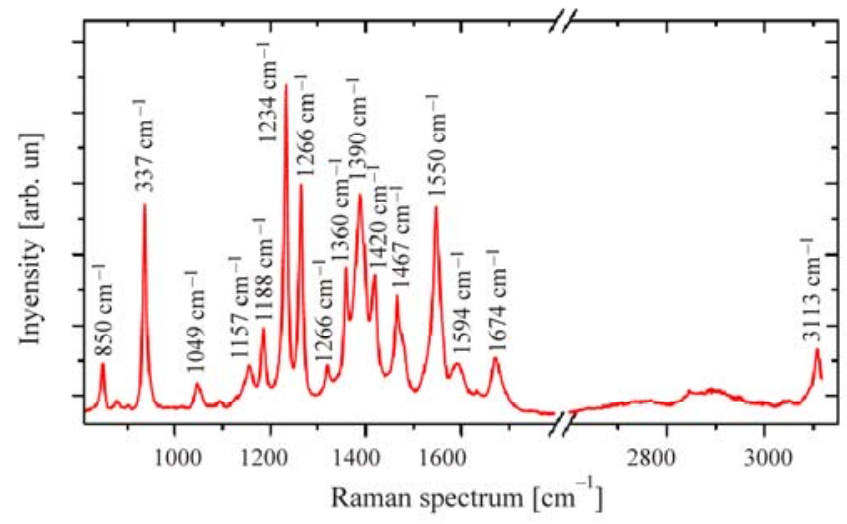

$\sigma$

Рис. 2. Спектры КРС Candida albicans: $a$ - спектры КРС трех групп, усреднённые по всем измеренным клеткам, интенсивность спектров нормировалась на пик фенилаланина (Phe); $\sigma$ - разностный спектр для средних спектров групп с1 и с2 
Спонтанная люминесценция при кратковременной фокусировке на клетке (до 3 мин) отсутствовала, что свидетельствует об отсутствии заметного влияния лазерного излучения на них. В спектрах КРС контрольных образцов были обнаружены интенсивные линии, относящиеся к неидентифицированному соединению. Однако поскольку частоты и соотношения интенсивностей линий не соответствуют ни липидам, ни белкам, ни нуклеиновым кислотам, их дальнейший анализ не проводился.

Исследования ультратонких срезов в электронном микроскопе выявили, что интактные клетки C. albicans имеют округлую форму и цитоплазму высокой электронной плотности, в которой плохо различаются органоиды (рис. $3, a$ ). Клетки окружены жесткой клеточной стенкой, которая на электронограммах выглядит гомогенной. Воздействие излучения при проведении исследования методом КРС не привело к разрушению клеточной стенки, но вызвало изменения ультраструктуры клеточных органоидов (рис. 3, б, в). Заметно снизилась электронная плотность цитоплазмы, в которой визуализируются ядро и органоиды, появились участки просветления цитоплазмы. Следует отметить изменение структуры клеточной стенки, в которой наблюдался отчётливый слой средней электронной плотности.

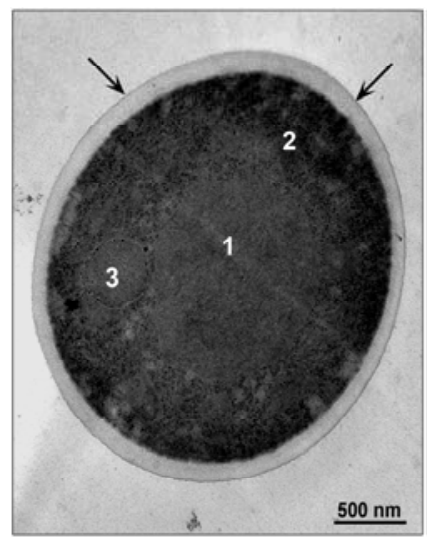

$a$

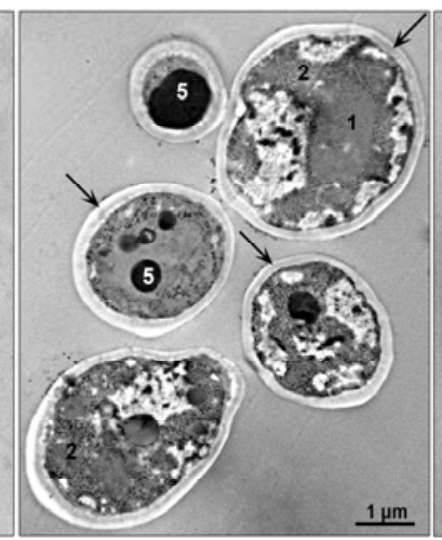

6

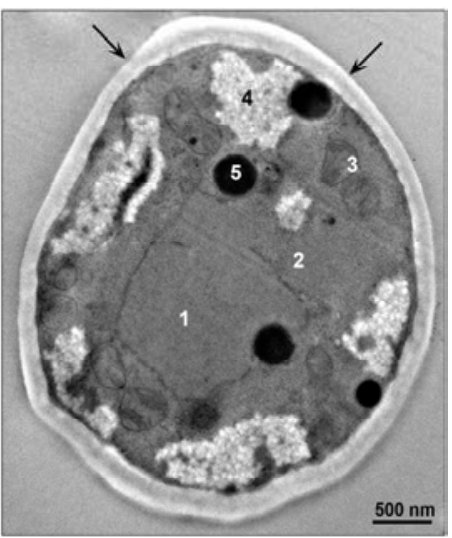

B

Рис. 3. Ультратонкие срезы клеток C. Albicans: $a$ - интактная клетка, $\sigma$, в - клетка после воздействия излучения 1064 нм мощностью 120 мВт и временем экспозиции 3 ч (экспозиция 1,3 кДж) (стрелкой показана клеточная стенка: 1 - ядро; 2 - цитоплазма; 3 - митохондрии; 4 - участки просветления цитоплазмы; 5 - липидные капли) 


\section{Заключение}

Проведенное исследование показало возможность получения спектров КРС клеток Candida albicans на оригинальной установке (схема приведена на рис. 1). Использованные параметры лазерного излучения не вызывали выраженных деструктивных изменений клеток, которые сохраняли свою целостность и клеточные органоиды. Выявленные изменения спектров образцов с1 и с2 свидетельствуют о влиянии длительной инкубации Candida albicans при $4{ }^{\circ} \mathrm{C}$ на химический состав её клеток, что необходимо учитывать при проведении микробиологических экспериментов. Инкубация Candida albicans с пептидом $\mathrm{Arg}_{9} \mathrm{Phe}_{2}$ привела к изменению формы и высоты пиков спектров, что свидетельствует об информативности спектроскопии КРС, однако интерпретация этих изменений требует дополнительных исследований.

Работа выполнена при поддержке проекта о 38 (0319-2017-0011) комплексной программы фундаментальных научных исследований СО РАН «Междисииплинарные интеграционные исследования» включая блок «Визуализачия диагностически значимых веществ с помощью пико- и фемтосекундных волоконных лазеров в модельных бесклеточных системах и в культурах клеток». Авторы также выражают благодарность К. А. Окотрубу за помощь в измерении спектров КРС и участие в обсуждении результатов.

\section{Список литературы}

1. Poulain D. Candida albicans, plasticity and pathogenesis // Crit. Rev. Microbiol. - 2015. - № 41(2). - P. 208-217.

2. Odds F.C. Morphogenesis in Candida albicans // Crit. Rev. Microbiol. - 1985. - № 12(1). - P. 45-93.

3. Membrane Active Antimicrobial Peptides: Translating Mechanistic Insights to Design / J. Li, J.J. Koh, S. Liu, R. Lakshminarayanan, C.S. Verma, R.W. Beuerman // Front. Neurosci. - 2017. - № 11. - P.73.

4. Okotrub K.A., Surovtsev N.V. Photobleaching of the resonance Raman lines of cytochromes in living yeast cells // J. Photochem Photobiol B. - 2014. - № 41. - P. 269-74.

5. Okotrub K.A., Surovtsev NV. Redox State of Cytochromes in Frozen Yeast Cells Probed by Resonance Raman Spectroscopy // Biophys J. 2015. - № 109(11). - P. 2227-34. 
6. Амирханов Н.В., Тикунова Н.В., Пышный Д.В. Синтетические антимикробные пептиды // Биоорганическая химия. - 2018. - № 44(5). C. 492-505.

\section{References}

1. Poulain D. Candida albicans, plasticity and pathogenesis. Crit. Rev. Microbiol., 2015, no. 41(2), pp. 208-217.

2. Odds F.C. Morphogenesis in Candida albicans. Crit. Rev. Microbiol., 1985, no. 12(1), pp. 45-93.

3. Li J., Koh J.J., Liu S., Lakshminarayanan R., Verma C.S., Beuerman R.W. Membrane active antimicrobial peptides: translating mechanistic insights to design. Front. Neurosci, 2017, no. 11, p. 73.

4. Okotrub K.A., Surovtsev N.V. Photobleaching of the resonance Raman lines of cytochromes in living yeast cells. J. Photochem Photobiol B, 2014, no. 41, pp. 269-274.

5. Okotrub K.A., Surovtsev NV. Redox state of cytochromes in frozen yeast cells probed by resonance Raman spectroscopy. Biophys J., 2015, no. 109(11), pp. 2227-2234.

6. Amirkhanov N.V., Tikunova N.V., Pyshnyi D.V. Sinteticheskie antimikrobnye peptidy [Synthetic Antimicrobial Peptides]. Bioorganicheskaia khimiia, 2018, no. 44(5), pp. 492-505.

Получено 06.11.19 